\title{
Interaction Between Bronchiolitis Diagnosed Before 2 Years of Age and Socio-Economic Status for Bronchial Hyperreactivity
}

\author{
Jong Han Leem'1, Hwan Cheol Kim', Ji Young Lee'2, Jong-Ryeul Sohn³ \\ ${ }^{1}$ Department of Occupational and Environmental Medicine, Inha University College of Medicine, Incheon; ' 2 Department of Preventive Medicine, \\ Inha University College of Medicine, Incheon; ' ${ }^{3}$ Department of Environmental Health, Korea University College of Health Sciences, Seoul, Korea
}

Objects: The prevalence of asthma has increased in recent decades globally. The objective of the present study is to elucidate whether hospitalization for bronchiolitis in infancy and low socioeconomic status interact for bronchial hyperreactivity during teenage years.

Method: We studied 522 children age 13-14 years attending schools in rural and urban areas to investigate the risk factors for bronchial hyperreactivity (BHR), defined as a provocation concentration of methacholine that causes a decrease of $20 \%$ (PC20) in forced expiratory volume within 1 second. Clinical examination, skin prick test, spirometry, and methacholine challenge were performed on all study subjects, who provided written consent. We used multivariate logistic regression to investigate the risk factors for BHR, and analyze the interaction between hospitalization for bronchiolitis in infancy and low socioeconomic status.

Results: Forty-six (10.3\%) positive BHR cases were identified. In the multivariate logistic analysis, as independent predictors of BHR, adjusted odds ratio of bronchiolitis diagnosed before 2 years of age in low income families was 13.7 (95\% confidence interval, 1.4 to 135.0), compared to reference group, controlling for age, gender, parental allergy history, skin prick test, and environmental tobacco smoke (ETS) exposure. Interaction was observed between bronchiolitis before 2 years old and low socioeconomic status on children's bronchial hyperreactivity ( $p$-interaction $=0.025)$.

Conclusions: This study showed that bronchiolitis diagnosed before 2 years of age and low socioeconomic status interacted on children's bronchial hyperreactivity. Prevention of acute respiratory infection in early childhood in low socioeconomic status is important to prevent BHR as a precursor of asthma.

Key words: Asthma, Bronchial hyperreactivity (BHR), Bronchiolitis, Children, Socioeconomic status

\section{INTRODUCTION}

The prevalence of asthma has increased during recent decades all over the world, and it is still rising in developed countries. However, the economic and precautionary effects of asthma are likely greater in the developing world, where the prevalence is also rising [1]. Primary prevention strategies to combat the asthma epidemic are therefore urgently sought, but they must be based on a sound understanding of the various determinants of the onset of asthma. Nonspecific bronchial hyperreactivity (BHR) is an important feature of asthma, and its identification has been used in the research field to strengthen the assessment of possible asthma. Comparison of risk factor profiles for wheezing, asthma, and BHR could facilitate a better understanding of the mechanisms underlying these conditions as well as of their similarities and differences.

Bronchiolitis is defined as a lower respiratory infection (LRI) in infants usually caused by virus. Acute viral bronchiolitis is one of the most common causes of hospitalization during infancy. Wheezing is common in infants and young children who suffer from LRI caused by different viruses, such as respiratory syncytial virus (RSV), rhinovirus and so on. There is some evidence that early-life bronchiolitis may predispose some infants to the development of childhood asthma [2-4]. However, risk factors for later lung function abnormalities or for the persistence of BHR after wheezing in infancy have rarely been studied.

The objective of our study is to elucidate whether

Correspondence: Jong Han Leem, MD, PhD

7-206 3rd St. Shinhung-dong, Jung-gu, Incheon 400-711, Korea

Tel: +82-32-890-3539, Fax: +82-32-890-2859

E-mail: ekeeper@inha.ac.kr

Received: Mar 23, 2011, Accepted: Jul 19, 2011, Published Online: Aug 28, 2011 This article is available from: http://e-eht.org/ 
hospitalization for bronchiolitis in infancy and low socioeconomic status (SES) interact for bronchial hyperreactivity during teenage years.

\section{METERIALS AND METHODS}

\section{Study Subjects}

We studied 522 children age 13-14 years attending schools in rural and urban areas to investigate the risk factors for BHR, defined as a provocation concentration of methacholine that caused a decrease of $20 \%$ (PC20) in forced expiratory volume within 1 second. Survey questionnaire, clinical examination, skin prick test, spirometry, and methacholine challenge were performed on only students, who provided written consent. Written consent was obtained from the parents of the subjects. Finally, 522 students completed survey questionnaire, 474 student performed BHT, and 449 students got skin prick test.

\section{Skin Prick Test (SPT)}

Subjects underwent SPT with a battery of 14 allergens including grass, tree, and weed pollens, dust mites (Dermatophagoides pteronyssinus and farinae), dog and cat epithelium, moulds (Aspergillus fumigates and Alternaria alternata), peanut, milk, egg, and bean (Allergopharma Co, Germany). The SPTs were performed on the forearm using an ALK-Lancet (ALK-Abello, Horsholm, Denmark). Negative and positive control tests were performed with $50 \%$ glycerine-saline and histamine $(10 \mathrm{mg} / \mathrm{mL})$, respectively. After 15 minutes, the skin prick weal induced by allergens and the negative and positive controls were outlined and copied onto permanent records with adhesive cellotape; the orthogonal diameters were subsequently measured. A positive SPT result was defined as a weal at least $3 \mathrm{~mm}$ larger than the diameter of the negative control. All subjects avoided short-acting antihistamines for 72 hours, long-acting antihistamines for 5 days, and tricyclic antidepressants for 2 weeks before STP [5].

\section{Methacholine Challenge Test (MCT)}

After inhaling an initial control solution of isotonic saline solution, study subjects were administered doubling concentrations of methacholine, starting from 0.0625 $\mathrm{mg} / \mathrm{mL}$, up to $16 \mathrm{mg} / \mathrm{mL}$ (if no response), by a dosimeter . All the spirometries were conducted on a KoKo Pneumotach Spirometer (Susquehanna Micro, Inc.; Red Lion, PA, USA), as previously described [4]. The variables measured were forced vital capacity (FVC), forced expiratory volume (FEV)1, and mid-expiratory flow (FEF25-75). During the
MCT, FEV1 values were measured 1 minute after the end of the corresponding inhalation. Each FEV1 measurement was expressed as a percentage from the baseline record. The provocation concentration of methacholine, defined as causing a decrease of $20 \%$ in FEV1 (PC20), was recorded. According to the standard protocol in our institute, all study subjects were instructed to stop any antiasthma medication before MCT. The washout period was 12 hours for shortterm beta-agonists, 48 hours for long-term beta-agonists, and 7 days for inhaled corticosteroids. If the provocation concentration of methacholine, defined as causing a decrease of $20 \%$ in FEV1 (PC20), is less than $16 \mathrm{mg} / \mathrm{ml}$, it is diagnosed as a positive methacholine test.

\section{Statistical Analysis}

Continuous variables were summarized by central tendency measures (mean or median), together with a dispersion measure such as standard deviation or range.

Categorical variables were described by their distribution of frequencies and percentages, both globally and in special interest subgroups. Comparison between groups was performed by using a Chi-square test and Fisher's exact test. We considered p-value of 0.05 as significant level.

Multivariable logistic regression model was used to investigate the risk factors for BHR. The odds ratios are shown with Wald's 95\% confidence intervals (CI). Statistical analyses were done using SPSS version 15.0 (SPSS, Inc., Chicago, IL, USA).

\section{RESULTS}

The study subjects included 182 males and 340 females, with ages ranging between 13 and 14 years.

148 students $(28.4 \%)$ have paternal allergy, 374 students $(71.6 \%)$ have no paternal allergy. Some students did not provide the information about paternal education level (5 students) and family incomes (11 students). At final analysis, they are excluded. 1 student $(0.2 \%)$ has a paternal education level of no years, 6 students $(1.2 \%)$ have a paternal education level of less than 6 years, 29 students (5.6\%) have a paternal education level of less than 9 years, and 231 students $(44.6 \%)$ have a paternal education level of less than 12 years. 229 students $(44.3 \%)$ have a paternal education level of education less than 16 years, and 21 students (4.1\%) have a paternal education level of education more than 16 years. 180 students $(35.2 \%)$ have family incomes of less than 1.5 million won monthly, 244 students $(47.8 \%)$ have family incomes of 1.5-3.0 million won monthly, and 87 students $(17.0 \%)$ have family incomes of more than 3.0 million won monthly.

The age in subgroup in the rural area (Pocheon) is from 13 
Table 1. Characteristics of study population

\begin{tabular}{|c|c|c|c|c|c|}
\hline $\begin{array}{l}\text { Variable/ } \\
\text { subgroup }\end{array}$ & $\begin{array}{l}\text { Total } \\
\mathrm{n}(\%)\end{array}$ & $\begin{array}{l}\text { Rural } \\
\text { area } \\
\text { (Pocheon) }\end{array}$ & $\begin{array}{l}\text { Urban } \\
\text { area A } \\
\text { (Seoul) }\end{array}$ & $\begin{array}{l}\text { Urban } \\
\text { area B } \\
\text { (Seoul) }\end{array}$ & $p$-value* \\
\hline \multicolumn{6}{|l|}{ Age (y) } \\
\hline 13 & $436(83.5)$ & 27 & 190 & 219 & $<0.01$ \\
\hline 14 & $86(16.5)$ & 86 & & & \\
\hline \multicolumn{6}{|l|}{ Gender } \\
\hline Male & $182(34.9)$ & 43 & 57 & 82 & 0.209 \\
\hline Female & $340(65.1)$ & 70 & 133 & 137 & \\
\hline \multicolumn{6}{|c|}{ Parental allergy history } \\
\hline Yes & $148(28.4)$ & 29 & 59 & 60 & 0.554 \\
\hline No & $374(71.6)$ & 84 & 131 & 159 & \\
\hline \multicolumn{6}{|c|}{ Father's education level (y) } \\
\hline$<9$ & $36(7.0)$ & 12 & 10 & 14 & $<0.001$ \\
\hline $9-<12$ & $231(44.6)$ & 74 & 49 & 108 & \\
\hline $12-<16$ & $229(44.3)$ & 21 & 121 & 87 & \\
\hline $16+$ & $21(4.1)$ & 4 & 8 & 9 & \\
\hline \multicolumn{6}{|c|}{ Family incomes (million won/month) } \\
\hline$<1.5$ & $180(35.2)$ & 53 & 52 & 75 & 0.014 \\
\hline $1.5-3$ & $244(47.8)$ & 50 & 93 & 101 & \\
\hline$>3$ & $87(17.0)$ & 6 & 42 & 39 & \\
\hline \multicolumn{6}{|c|}{ Exposure to ETS } \\
\hline No & $318(65.3)$ & 72 & 123 & 123 & 0.072 \\
\hline Yes & $169(34.7)$ & 35 & 51 & 83 & \\
\hline \multicolumn{6}{|c|}{ Skin prick test to cockroach } \\
\hline No & $284(63.3)$ & 56 & 99 & 135 & 0.684 \\
\hline Yes & $165(36.7)$ & 24 & 58 & 83 & \\
\hline
\end{tabular}

ETS: environmental tobacco smoke

* tested by $\chi 2$-test.

years to 14 years old, while that in urban A and urban B in Seoul is 13 years old. Gender ratio is not different between the three subgroups. The rate of having a parental allergy is not different between the three subgroups. However, factors related to socioeconomic status including father's education level and family's incomes are significantly different (Table 1).

Positive BHR is defined as a provocation concentration of methacholine that causes a decrease of $\mathrm{PC}_{20}$ in forced expiratory volume in 1 second. When $\mathrm{PC}_{20}$ is less than 8 $\mathrm{mg} / \mathrm{dL}$, there are 18 (3.8\%) positive BHR cases. When $\mathrm{PC}_{20}$ is less than $16 \mathrm{mg} / \mathrm{dL}$, there are $47(9.9 \%)$ positive BHR cases. Urban B area having low socioeconomic status shows the highest positive BHR rate at $16.9 \%$ (Table 2).

In the univariate logistic analysis, as independent predictors of BHR, crude odds ratio of bronchiolitis diagnosed before 2 years of age was 2.39 (95\% CI, 0.85 to 6.74), compared to reference group who did not experience bronchiolitis diagnosed before 2 years of age. And crude odds ratio of low family income less than 1.5 million won per month, was 1.49 (95\% CI, 0.81 to 2.78), compared to reference group who have family income more than 1.5 million won per month.

In the multivariate logistic analysis, as independent predictors of BHR, adjusted odds ratio of bronchiolitis diagnosed before 2 years of age was 3.42 (95\% CI, 1.03 to 11.33), compared to reference group, controlling for age, gender, parental allergy history, skin prick test, and Environmental tobacco smoke (ETS) exposure. Adjusted
Table 2. Bronchial hyperreactivity of study population

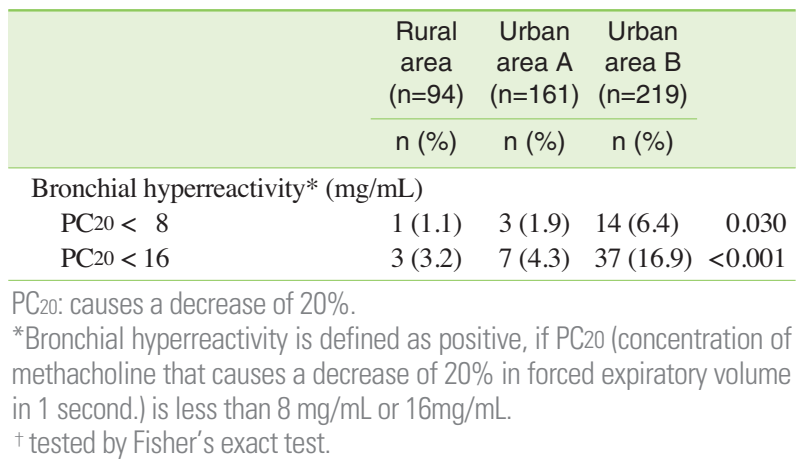

Table 3. Risk factors associated with bronchial hyperreactivity

\begin{tabular}{|c|c|c|c|}
\hline & $\mathrm{n}(\%)$ & cOR $95 \% \mathrm{Cl}$ & aOR $95 \% \mathrm{Cl}$ \\
\hline \multicolumn{4}{|l|}{ Age (y) } \\
\hline 13 & $436(83.5)$ & 1.00 & 1.00 \\
\hline 14 & $86(16.5)$ & $0.27(0.06,1.14)$ & $0.16(0.02,1.26)$ \\
\hline \multicolumn{4}{|l|}{ Gender } \\
\hline Male & $182(34.9)$ & 1.00 & 1.00 \\
\hline Female & $340(65.1)$ & $1.57(0.79,3.13)$ & $2.19(1.08,5.86)$ \\
\hline \multicolumn{4}{|c|}{ Parental allergy history } \\
\hline No & $148(28.4)$ & 1.00 & 1.00 \\
\hline Yes & $374(71.6)$ & $1.55(0.82,2.93)$ & $2.05(0.97,4.33)$ \\
\hline \multicolumn{4}{|l|}{ Area } \\
\hline Rural & $113(21.6)$ & 1.00 & 1.00 \\
\hline Urban A & $190(36.4)$ & $1.67(0.34,8.23)$ & $1.30(0.24,7.20)$ \\
\hline Urban B & $219(42.0)$ & $7.26(1.70,30.91)$ & $6.28(1.39,29.39)$ \\
\hline \multicolumn{4}{|c|}{ Father's education (y) } \\
\hline $12+$ & $250(48.4)$ & 1.00 & 1.00 \\
\hline $9-<12$ & $231(44.6)$ & $0.89(0.46,1.72)$ & $0.54(0.23,1.27)$ \\
\hline$<9$ & $36(7.0)$ & $1.76(0.61,5.07)$ & $1.01(0.26,3.98)$ \\
\hline \multicolumn{4}{|c|}{ Family income (million won per month) } \\
\hline $1.5<$ & $331(64.8)$ & 1.00 & 1.00 \\
\hline$<1.5$ & $180(35.2)$ & $1.49(0.81,2.78)$ & $2.55(1.15,5.67)$ \\
\hline \multicolumn{4}{|c|}{ Exposure to ETS } \\
\hline No & $318(65.3)$ & 1.00 & 1.00 \\
\hline Yes & $169(36.7)$ & $1.84(0.97,3.51)$ & $1.53(0.73,3.22)$ \\
\hline \multicolumn{4}{|c|}{ Skin prick test to cockroach } \\
\hline No & $284(63.3)$ & 1.00 & 1.00 \\
\hline Yes & $165(36.7)$ & $1.20(0.63,2.29)$ & $0.99(0.46,2.16)$ \\
\hline \multicolumn{4}{|c|}{ Bronchiolitis before 2 years old } \\
\hline No & $482(94.1)$ & 1.00 & 1.00 \\
\hline Yes & $30(5.9)$ & $2.39(0.85,6.74)$ & $3.42(1.03,11.33)$ \\
\hline
\end{tabular}

OR: odds ratio, Cl: confidence interval, ETS: environmental tobacco smoke. COR: univariate logistic regression, aOR: multivariate logistic regression adjusted for age, gender, area, parental allergy history, skin prick test, and ETS exposure.

odds ratio of low family income less than 1.5 million won per month was 2.55 (95\% CI, 1.15 to 5.67), controlling for age, gender, parental allergy history, area, skin prick test, and ETS. Female children were also vulnerable group to bronchial hyperreactivity. Adjusted odds ratio of female children was is 2.19 (95\% CI, 1.08 to 5.86) compared to male children, controlling for age, parental allergy history, bronchiolitis diagnosed before 2 years of age, area, skin prick test, and ETS exposure (Table 3). 
Table 4. Joint effect of bronchiolitis before 2 years old and socioeconomic status on children' $s$ bronchial hyperreactivity

\begin{tabular}{ccccc}
\hline $\begin{array}{c}\text { Brochiolitis before } \\
2 \text { years old }\end{array}$ & $\begin{array}{c}\text { Family income } \\
\text { (million won per month) }\end{array}$ & $\mathrm{n}(\%)$ & cOR 95\% Cl & aOR 95\% Cl \\
No & $1.5<$ & $311(60.7)$ & 1.0 & 1.0 \\
No & $<1.5$ & $171(33.4)$ & $1.9(0.6,7.5)$ & $2.6(0.6,10.5)$ \\
Yes & $1.5<$ & $25(4.9)$ & $1.5(0.7,2.8)$ & $2.0(0.9,4.2)$ \\
Yes & $<1.5$ & $5(1.0)$ & $11.1(1.5,80.6)$ & $13.7(1.4,135.0)$ \\
& & & & p-interaction=0.025
\end{tabular}

OR: odds ratio, $\mathrm{Cl}$ : confidence interval.

cOR: univariate logistic regression, aOR: multivariate logistic regression adjusted for age, gender, area, parental allergy history, skin prick test, and environmental tobacco smoke exposure.

To investigate joint effect of bronchiolitis before 2 years old and low socioeconomic status on children's bronchial hypersensitivity, interaction between them was explored. In the multivariate logistic analysis, as independent predictors of BHR, adjusted odds ratio of bronchiolitis diagnosed before 2 years of age in low income families was 13.7 (95\% CI, 1.4 to 135.0), compared to reference group, controlling for age, gender, parental allergy history, skin prick test, and ETS exposure (Table 4). Interaction was observed between bronchiolitis before 2 years old and low socioeconomic status on children's bronchial hyperreactivity ( $\mathrm{p}$-interaction $=0.025$ )

\section{DISCUSSION}

Hospitalization for bronchiolitis in infancy has been linked with lung function abnormalities [4,6], reactive airways [7-9] and atopic asthma [10] until 10-13 years of age. Infants with wheezing severe enough to require hospitalization seem to be vulnerable groups with host-specific characteristics, which modify their responses to viral infections [11].

This raises the question of what are the host-specific characteristics of vulnerable groups? While the scope of modifying genetic influences is still limited, attention has focused on environmental factors that can be changed by feasible interventions. Thus, we should have interest on numerous influences as the potential causes for childhood asthma, including early allergen exposure, method of infant feeding, viral respiratory infection, environmental tobacco smoke exposure, and pet contact.

Asthma and bronchial hyperreactivity, after many nonsymptomatic years, have a tendency to recur in early adulthood [12]. Therefore, minor changes in lung function or in bronchial reactivity, though clinically nonsignificant, may be useful predictors of subsequent morbidity. Our study found that bronchiolitis diagnosed before 2 years of age in low income families can be an important risk factor of bronchial hypersensitivity. In that point, we found that bronchiolitis diagnosed before 2 years of age and SES, such as low income families, interact to modify bronchial responsiveness mutually. We established regression analysis to validate their interaction. Our study is unique in demonstrating the interaction between bronchiolitis diagnosed before 2 years of age and SES statistically. Our study has some limitations. This study is cross-sectional, not a cohort study. Viral infections were not studied by antigen detection in the nasopharyngeal aspirates obtained during hospitalization and antibody determination in sera in this study. There may be recall bias in our study. But, we checked closely whether bronchiolitis was diagnosed by doctor, and bronchiolitis, usually caused by respiratory syncytial virus (RSV) and rhinovirus infection, is an important cause of severe lung disease in infants, it is less likely that recall bias may be involved in this study.

There are increasing evidence suggests that it is immunologically mediated. Experiments in mice suggest that this may be due to differential T-cell activation producing either type 1 or type 2 cytokines. This hypothesis is also supported in patients with severe RSV bronchiolitis, by measuring messenger RNA (mRNA) for interleukin-4 (IL-4) and interferon-gamma (IFN-gamma), by polymerase chain reaction, in nasopharyngeal aspirates (NPAs) and bronchoalveolar lavage (BAL) fluids. These findings provide the first direct evidence in infants that in RSV bronchiolitis there are divergent T-cell responses and suggest that more than one mechanism may be responsible for immune-mediated disease enhancement [13].The combination of atopic heredity and elevated cord blood IgE resulted in the best predictive discrimination with regard to the development of allergic disease [14].

In the study of Wennergren et al., 37\% of <24-month-old children hospitalized for bronchiolitis had abnormal results in histamine challenge at the age of 10 years, the figure being between our BHR values obtained by two measures, $26 \%$ for exercise and $46 \%$ for the methacholine challenge, at an average of 12.3 years of age. Wennergren et al did not find any association between early atopy and asthma or BHR at the age of 10 years [10]. In our study and another study [15], instead, the positive skin prick test was a significant predictor of activity teenagers. Atopic asthmatic schoolchildren have greater hyperreactivity to methacholine than nonatopics [16]. Our findings are in accordance with a recent birth cohort study from Germany [17], in which BHR at school age was significantly associated with sensitization to perennial allergens in early life, particularly in those children who suffered from current wheezing. 
Families with low socioeconomic status are susceptible to numerous environmental hazards [18-20].

In a meta-analysis including 22 studies, maternal smoking was associated with small but statistically significant deficits in lung function in school-aged children [21]. The prevalence of smoking and nicotine addiction among parents of children with asthma or bronchiolitis who bring their children to a pediatric emergency department is high [22].

In our study, we observed increased adjusted odds ratio of current ETS exposure on BHR at late school age, which was not significant statistically. Although there is some evidence that in utero exposure to tobacco smoke may increase bronchial responsiveness continuing through childhood [23], many factors, such as early-life passive smoking and later active smoking, complicate the interpretation of the results [20,24]. A recent Swedish long-term follow-up study after bronchiolitis in infancy stressed the link between early-life tobacco smoke exposure, later BHR, and later asthma [25]. Early passive smoking was an independent risk factor for BHR and for active smoking at young adult age, and both were associated with chronic asthma [22].

Taking all these things into consideration, ETS operates as a cofactor with other insults such as intercurrent infections as a trigger of wheezing attacks, rather than as a factor that induces asthma, whereas in utero exposure acts to increase physician-diagnosed asthma.

Carroll et al. [26] reported a negative association between increasing birth weight and bronchiolitis diagnosis. LBW is associated with higher risk of being hospitalized for bronchiolitis in infancy [27].

People with low SES are more vulnerable to air pollution than others. They are exposed to infection, nutritionally deficient, and often lived in more polluted area.

Nutrition status can be acting as a effect modifier between exposures to airborne particulate matter and asthma [28,29]. Earnst et al. reported that among factors potentially linked to SES, the presence of a cat at home (OR, 1.63; 95\% CI, 1.02 to 2.61) and lower respiratory infection before 2 years of age were associated with an excess of exercise-induced bronchospasm (OR, 1.71; 95\% CI, 1.16 to 2.52). The results suggest that unidentified environmental factors contribute to the excess asthma morbidity in poor children [30]. Environmental exposures may contribute to racial disparities in asthma. Hispanic, African-American, and Asian/Pacific Islander mothers experienced higher mean levels of air pollution and were more than twice as likely to live in the most polluted counties compared with white mothers after controlling for maternal risk factors, region, and educational status [Hispanic mothers: AOR, 4.66; 95\% CI, 1.92 to 11.32 ; African-American mothers: AOR, 2.58; 95\% CI, 1.00 to 6.62; Asian/Pacific Islander mothers: AOR, 2.82; 95\% CI, 1.07 to 7.39$]$ [31].

These findings may provide some support for the association between income inequality and BHR.
There is a global epidemic of increasing asthma, atopic dermatitis, and other allergic diseases, in developing and developed countries. The epidemic will continue to increase and is due to a lifetime of exposures and influences [32-34]. Further study will be needed to validate the association between being hospitalized in infancy and BHR for reinforcing preventive strategies throughout life, starting in the antenatal and perinatal period.

\section{CONCLUSIONS}

This study showed that bronchiolitis diagnosed before 2 years of age and low socioeconomic status interacted on children's bronchial hyperreactivity. Prevention of acute respiratory infection in early childhood, especially in low income families, is important to prevent BHR, a precursor of asthma.

\section{ACKNOWLEDGEMENTS}

This study was supported as Eco-R \& D by Korea Environmental Industry \&Technology Institute.

\section{CONFLICT OF INTEREST}

The authors have no conflict of interest to declare on this study.

\section{REFERENCES}

1. Eder W, Ege MJ, von Mutius E. The asthma epidemic. N Engl J Med 2006; 355(21): 2226-2235.

2. Carlsen KH, Larsen S, Orstavik I. Acute bronchiolitis in infancy. The relationship to later recurrent obstructive airways disease. Eur J Respir Dis 1987; 70(2): 86-92.

3. Kotaniemi-Syrjanen A, Reijonen TM, Korhonen K, Korppi M. Wheezing requiring hospitalization in early childhood: predictive factors for asthma in a six-year follow-up. Pediatr Allergy Immunol 2002; 13(6): 418-425.

4. Sigurs N, Gustafsson PM, Bjarnason R, Lundberg F, Schmidt S, Sigurbergsson F, et al. Severe respiratory syncytial virus bronchiolitis in infancy and asthma and allergy at age 13. Am J Respir Crit Care Med 2005; 171(2): 137-141.

5. Bernstein IL, Li JT, Bernstein DI, Hamilton R, Spector SL, Tan R, et al. Allergy diagnostic testing: an updated practice parameter. Ann Allergy Asthma Immunol 2008; 100(3 Suppl 3): S1-S148.

6. Noble V, Murray M, Webb MS, Alexander J, Swarbrick AS, Milner AD. Respiratory status and allergy nine to 10 years after acute bronchiolitis. Arch Dis Child 1997; 76(4): 315-319.

7. Sigurs N, Aljassim F, Kjellman B, Robinson PD, Sigurbergsson $\mathrm{F}$, Bjarnason R, et al. Asthma and allergy patterns over 18 years 
after severe RSV bronchiolitis in the first year of life. Thorax 2010; 65(12): 1045-1052.

8. Jackson DJ, Gangnon RE, Evans MD, Roberg KA, Anderson EL, Pappas TE, et al. Wheezing rhinovirus illnesses in early life predict asthma development in high-risk children. Am J Respir Crit Care Med 2008; 178(7): 667-672.

9. Wennergren G, Amark M, Amark K, Oskarsdottir S, Sten G, Redfors S. Wheezing bronchitis reinvestigated at the age of 10 years. Acta Paediatr 1997; 86(4): 351-355.

10. Jartti T, Kuusipalo H, Vuorinen T, Soderlund-Venermo M, Allander T, Waris M, et al. Allergic sensitization is associated with rhinovirus-, but not other virus-, induced wheezing in children. Pediatr Allergy Immunol 2010; 21(7): 1008-1014.

11. Martinez FD. Heterogeneity of the association between lower respiratory illness in infancy and subsequent asthma. Proc Am Thorac Soc 2005; 2(2): 157-161.

12. Piippo-Savolainen E, Remes S, Kannisto S, Korhonen K, Korppi M. Asthma and lung function 20 years after wheezing in infancy: results from a prospective follow-up study. Arch Pediatr Adolesc Med 2004; 158(11): 1070-1076.

13. Mobbs KJ, Smyth RL, O'Hea U, Ashby D, Ritson P, Hart CA. Cytokines in severe respiratory syncytial virus bronchiolitis. Pediatr Pulmonol 2002; 33(6): 449-452.

14. Halken S. Prevention of allergic disease in childhood: clinical and epidemiological aspects of primary and secondary allergy prevention. Pediatr Allergy Immunol 2004; 15 (Suppl 16): 4-5, 9-32.

15. Hyvarinen MK, Kotaniemi-Syrjanen A, Reijonen TM, Korhonen K, Korppi MO. Teenage asthma after severe early childhood wheezing: an 11-year prospective follow-up. Pediatr Pulmonol 2005; 40(4): 316-323.

16. Castro-Rodriguez JA, Navarrete-Contreras P, Holmgren L, Sanchez I, Caussade S. Bronchial hyperreactivity to methacholine in atopic versus nonatopic asthmatic schoolchildren and preschoolers. J Asthma 2010; 47(8): 929-934.

17. Illi S, von Mutius E, Lau S, Niggemann B, Gruber C, Wahn U, et al. Perennial allergen sensitisation early in life and chronic asthma in children: a birth cohort study. Lancet 2006; 368(9537): 763-770.

18. Valdivia C G, Caussade L S, Navarro M H, Cerda L J, Pérez B $\mathrm{E}$, Aquevedo $\mathrm{S} \mathrm{A}$, et al. Changes in asthma prevalence among school children during a 6-year period: Influence of socioeconomic status. Rev Med Chil 2009; 137(2): 215-225.

19. Mielck A, Reitmeir P, Wjst M. Severity of childhood asthma by socioeconomic status. Int J Epidemiol 1996; 25(2): 388-393.

20. Soto-Quiros ME, Soto-Martinez M, Hanson LA. Epidemiological studies of the very high prevalence of asthma and related symptoms among school children in Costa Rica from 1989 to
1998. Pediatr Allergy Immunol 2002; 13(5): 342-349.

21. Cook DG, Strachan DP, Carey IM. Health effects of passive smoking. 9. Parental smoking and spirometric indices in children. Thorax 1998; 53(10): 884-893.

22. Mahabee-Gittens M. Smoking in parents of children with asthma and bronchiolitis in a pediatric emergency department. Pediatr Emerg Care 2002; 18(1): 4-7.

23. Cook DG, Strachan DP. Parental smoking, bronchial reactivity and peak flow variability in children. Thorax 1998; 53(4): 295301.

24. Lodrup Carlsen KC, Carlsen KH. Effects of maternal and early tobacco exposure on the development of asthma and airway hyperreactivity. Curr Opin Allergy Clin Immunol 2001; 1(2): 139-143.

25. Goksor E, Amark M, Alm B, Gustafsson PM, Wennergren G. Asthma symptoms in early childhood--what happens then? Acta Paediatr 2006; 95(4): 471-478.

26. Carroll KN, Gebretsadik T, Griffin MR, Wu P, Dupont WD, Mitchel EF, et al. Increasing burden and risk factors for bronchiolitis-related medical visits in infants enrolled in a state health care insurance plan. Pediatrics 2008; 122(1): 58-64.

27. Holman RC, Shay DK, Curns AT, Lingappa JR, Anderson LJ. Risk factors for bronchiolitis-associated deaths among infants in the United States. Pediatr Infect Dis J 2003; 22(6): 483-490.

28. Kitz R, Rose MA, Schubert R, Beermann C, Kaufmann A, Bohles HJ, et al. Omega-3 polyunsaturated fatty acids and bronchial inflammation in grass pollen allergy after allergen challenge. Respir Med 2010; 104(12): 1793-1798.

29. Woods RK, Walters EH, Raven JM, Wolfe R, Ireland PD, Thien FC, et al. Food and nutrient intakes and asthma risk in young adults. Am J Clin Nutr 2003; 78(3): 414-421.

30. Ernst P, Demissie K, Joseph L, Locher U, Becklake MR. Socioeconomic status and indicators of asthma in children. Am J Respir Crit Care Med 1995; 152(2): 570-575.

31. Woodruff TJ, Parker JD, Kyle AD, Schoendorf KC. Disparities in exposure to air pollution during pregnancy. Environ Health Perspect 2003; 111(7): 942-946.

32. Darnton-Hill I, Nishida C, James WP. A life course approach to diet, nutrition and the prevention of chronic diseases. Public Health Nutr 2004; 7(1A): 101-121.

33. Olden K, White SL. Health-related disparities: influence of environmental factors. Med Clin North Am 2005; 89(4): 721738.

34. Wahlqvist ML. Chronic disease prevention: a life-cycle approach which takes account of the environmental impact and opportunities of food, nutrition and public health policies - the rationale for an eco-nutritional disease nomenclature. Asia Pac J Clin Nutr 2002; 11(Suppl 9): S759-S762. 